\title{
Política e literatura: um estudo sobre Oswald de Andrade
}

\author{
Politics and Literature: A Study on Oswald de Andrade
}

Edvaldo Sotana*

\section{Carreri, Marcio Luiz}

O socialismo de Oswald de Andrade: cultura, política e tensões na modernidade de São Paulo na década de 1930

Curitiba: CRV, 2017. 164p.

O livro intitulado O socialismo de Oswald de Andrade é fruto da tese de doutorado desenvolvida por Marcio Carreri no Programa de Pós-graduação em História da Pontifícia Universidade Católica de São Paulo (PUC-SP). Algumas indagações motivaram a pesquisa do professor do curso de história da Universidade Estadual do Norte do Paraná (Uenp). Dentre elas, destacam-se: "Que contribuição um homem da cultura pode dar para as ideias políticas?" e "É possível situar Oswald de Andrade como um socialista, primeiramente como escritor e também como homem de ação e, fundamentalmente, reconhecer sua contribuição para o pensamento social brasileiro?" (Carreri, 2017, p.16).

Para realizar seu estudo sobre Oswald de Andrade, Carreri tomou como fonte o jornal O Homem do Povo (1931) e textos literários, como Serafim Ponte Grande (1933), O Rei da Vela (1933) e Marco Zero (1943 e 1946). Assim, a própria escolha do corpus documental enseja oportuna discussão sobre a relação entre história e literatura, principalmente no que diz respeito ao estatuto das representações literárias para a pesquisa histórica.

Cumpre destacar que seu livro não adquire caráter ensaístico ou de biografia ocupada em mitificar o personagem. Ao contrário, o estudioso demonstra ciência da difícil empreitada em posicionar o homem das letras entre as correntes do modernismo. Além disso, explicita certa mitologia construída em torno do literato e, também, a falta de "generosidade" da

* Professor Adjunto, Universidade Federal de Mato Grosso do Sul (UFMS), Campus de Aquidauana. Aquidauana, MS, Brasil. sotana.ufms@gmail.com 
crítica com seus textos ou a ausência de interlocução da sua obra com a militância política de esquerda.

De modo geral, seu trabalho está escudado em sólido e profícuo aporte teórico-metodológico. Pautado nos conceitos de cultura política (história política renovada) e de hegemonia (Antonio Gramsci), bem como na noção de estrutura de sentimento (Raymond Williams), o pesquisador confronta a tese socialista de Oswald de Andrade, os meios e os suportes que foram por ele utilizados. Sua investigação não visa, porém, apresentar "um filósofo marxista" ou que tenha "criado uma nova linguagem interpretativa", mas desvela "um militante revolucionário fundamental para se pensar a relação da cultura com a política ou a prática do socialismo" (Carreri, 2017, p.21).

Vale a pena destacar a tese do trabalho. Ao tomar a experiência intelectual como prática política, o estudioso ressalta:

Ainda que se atribua ao escritor paulista uma suposta timidez da formulação teórica, entende-se que Oswald desenvolveu, a partir de leituras e opções políticas, uma peculiar visão de mundo, uma original perspectiva de socialismo, e trabalhou por sua efetivação, em diferentes instituições, no partido político e no amplo cenário cultural paulistano e brasileiro ... O marxismo antropofágico, assim denominado, é a síntese socialista de Oswald, que, ainda que tenha sido vivida no período em que era membro do PCB, foi formulada antes (1928) e continuou presente em suas reflexões após o rompimento com o Partido (1945). Cultura e ação política, ambas em momentos diferentes da trajetória do escritor, são percebidas para a interpretação de sua formulação filosófica. (Carreri, 2017, p.26)

Ao longo de quatro capítulos, Carreri constrói um enredo para sustentar essa proposta. No primeiro, aborda os espaços públicos e privados nos quais Oswald de Andrade formulou suas reflexões e o processo de transformação da cidade de São Paulo entre o final da década de 1920 e a década de 1930, além de apresentar seus interlocutores, destacando, principalmente, aqueles que integraram a redação do jornal Homem do Povo - dentre eles, Patrícia Galvão (Pagu). No capítulo seguinte, faz uma análise sobre o estilo e a linguagem do escritor paulista. Tomar a ironia como arma na luta simbólica travada, tanto no espaço do modernismo quanto no campo da política, é ponto central na abordagem construída no segundo capítulo. O terceiro capítulo enfoca o socialismo de Oswald de Andrade, seus embates com o integralismo de Plínio 
Salgado e com os intelectuais que aderiram à chamada Revolução Constitucionalista de 1932. Já o último capítulo trata da atuação de Andrade como redator e editor do jornal Homem do Povo, sem, é claro, deixar de situar as controvérsias entre o escritor e o Partido Comunista do Brasil (PCB), tampouco com jornais de circulação nacional (O Estado de S. Paulo, por exemplo) e com estudantes do Largo São Francisco.

A propósito, a filiação, a militância e as tensões de Oswald de Andrade com o PCB são aspectos que chamam a atenção do leitor. Assim como outros intelectuais, Andrade estabeleceu uma complexa relação com a direção e as diretrizes partidárias. Como ocorreu, em momentos posteriores, com Graciliano Ramos e Caio Prado Júnior, ${ }^{1}$ o literato paulista realizou diferentes atividades partidárias sem, no entanto, deixar de tensionar com a direção pecebista em razão das orientações e normas partidárias para produção cultural. ${ }^{2}$

Junto a outros temas, a relação entre o intelectual e o partido foi objeto de discussão com base no jornal $O$ Homem do Povo. O periódico foi utilizado, igualmente, para pensar o projeto cultural, político e ideológico de Oswald, bem como as tensões marcantes na sua rede de sociabilidade:

Oswald de Andrade, recém-chegado ao Partido por força de um convite do próprio Prestes e da força mobilizadora do entusiasmo da companheira Pagu, publicou, por seu turno, o jornal OHP, com participação de intelectuais e militantes anarquistas e comunistas, apresentou-se à arena dos debates públicos, fornecendo seu ponto de vista para a reivindicação, no século XX, da identidade nacional brasileira. (Carreri, 2017, p.29)

Pensar a relação entre o intelectual e o partido leva o leitor a uma questão mais ampla: Quais as funções de um intelectual? De acordo com Sirinelli (1996, p.242-243), temos duas acepções referentes à noção de intelectual: uma ampla e sociocultural, englobando os criadores e os "mediadores" culturais, e outra mais estreita, baseada na ideia de engajamento do sujeito na vida da sociedade como ator, testemunha ou consciência política. Tomar Oswald de Andrade como um intelectual engajado na cidade de São Paulo, notadamente o modo como experimentou a modernidade e as práticas de sociabilidade construídas em determinados espaços na terra da garoa, a partir da década de 1930, é outro mérito do trabalho de Carreri. 
Enfim, construída a partir de pesquisa empírica, relevante discussão bibliográfica e consistente suporte teórico-metodológico, a obra pode ser considerada fundamental para o leitor interessado em Oswald de Andrade e nas interfaces entre história e literatura, mas também para os pesquisadores atentos às experiências culturais e políticas vivenciadas na cidade de São Paulo nas décadas de 1920 e 1930. Também pode cativar estudiosos ocupados em discutir a relação dos intelectuais com o PCB ou empenhados em cotejar a própria ideia de engajamento intelectual. Não obstante, o texto é um convite à reflexão sobre o papel dos intelectuais no Brasil contemporâneo - tarefa premente em razão da atual ausência de debate sobre projetos de nação e, principalmente, frente aos últimos acontecimentos da cena política brasileira. Parafraseando o autor, é uma obra para quem acredita "na capacidade da Academia e da Educação como um todo, em fornecer subsídios para o combate à crescente despolitização da sociedade" (Carreri, 2017, p.143). Fica, portanto, o convite para os interessados em cultura, política e militância intelectual, tanto nos idos da década de 1930 quanto no tempo presente.

\section{REFERÊNCIAS}

FERREIRA, Jorge Luiz. Prisioneiros do mito: cultura e imaginário político dos comunistas no Brasil (1930-1956). Tese (Doutorado em História) - Faculdade de Filosofia, Letras e Ciências Humanas, Universidade de São Paulo. São Paulo, 1996.

MORAES, Dênis de. O imaginário vigiado: a imprensa comunista e o realismo socialista no Brasil (1947-1953). Rio de Janeiro: J. Olympio Ed., 1994.

. O Velho Graça: uma biografia de Graciliano Ramos. Rio de Janeiro: J. Olympio Ed., 1993.

PALAMARTCHUK, Ana Paula. Os novos bárbaros: escritores e comunismo no Brasil (1928-1948). Tese (Doutorado em História Social) - Instituto de Filosofia e Ciências Humanas (IFCH), Universidade Estadual de Campinas (Unicamp). Campinas, 2003.

Ser intelectual comunista...: escritores brasileiros e comunismo (1920-1945).

Dissertação (Mestrado em História) - Instituto de Filosofia e Ciências Humanas (IFCH), Universidade Estadual de Campinas (Unicamp). Campinas, 1997.

RICUPERO, Bernardo. Caio Prado Júnior e a nacionalização do marxismo. São Paulo: Fapesp; Ed. 34, 2000. 
RUBIM, Antonio Albino Canelas. Partido Comunista, cultura e política cultural. Tese (Doutorado em Sociologia) - Faculdade de Filosofia, Letras e Ciências Humanas (FFLCH), Universidade de São Paulo (USP), 1986.

SIRINELLI, Jean-François. Os intelectuais. In: RÉMOND, René (Org.) Por uma história política. Rio de Janeiro: Ed. UFRJ, 1996. p.231-270.

\section{NOTAS}

${ }^{1}$ Para conhecer mais sobre a relação entre Graciliano Ramos e o PCB, sugerimos MORAES (1993). Sobre Caio Prado Júnior e o PCB, consultar RICUPERO (2000).

${ }^{2}$ Existem alguns estudos fundamentais para tratar da relação dos intelectuais com o PCB. Dentre eles, destacamos os trabalhos de PALAMARTCHUK $(1997 ; 2003)$ e a tese de RUBIM (1986). Apesar de ocupado com período posterior, o trabalho de MORAES (1994) também aborda a relação entre intelectuais e as diretrizes partidárias. Ainda para aprofundar o entendimento da questão, notadamente no que se refere ao estudo da cultura e do imaginário dos militantes comunistas brasileiros, o leitor pode consultar FERREIRA (1996).

Resenha recebida em 18 de setembro de 2017. Aprovada em 22 de março de 2018. 